\title{
Bruno Thibault, J.M.G. Le Clézio et la métaphore exotique
}

\section{Gianmaria Finardi}

\section{Q OpenEdition}

1 Journals

\section{Edizione digitale}

URL: http://journals.openedition.org/studifrancesi/6107

DOI: 10.4000/studifrancesi.6107

ISSN: 2421-5856

\section{Editore}

Rosenberg \& Sellier

\section{Edizione cartacea}

Data di pubblicazione: 1 mai 2011

Paginazione: 216

ISSN: 0039-2944

\section{Notizia bibliografica digitale}

Gianmaria Finardi, «Bruno Thibault, J.M.G. Le Clézio et la métaphore exotique», Studi Francesi [Online], 163 (LV | I) | 2011, online dal 30 novembre 2015, consultato il 14 janvier 2021. URL: http:// journals.openedition.org/studifrancesi/6107 ; DOI: https://doi.org/10.4000/studifrancesi.6107

Questo documento è stato generato automaticamente il 14 janvier 2021.

\section{(c) (i) (9)}

Studi Francesi è distribuita con Licenza Creative Commons Attribuzione - Non commerciale - Non opere derivate 4.0 Internazionale. 


\title{
Bruno Thibault, J.M.G. Le Clézio et la métaphore exotique
}

\author{
Gianmaria Finardi
}

\section{NOTIZIA}

BRUNO THIBAULT, J.M.G. Le Clézio et la métaphore exotique, Amsterdam-New York, Rodopi, 2009 («Collection monographique Rodopi en littérature française contemporaine», 49), pp. 241.

1 Nel presentare la problematica questione della collocazione del viaggio all'interno della scrittura di J.M.G. Le Clézio, questo studio mette in evidenza una delle tematiche fondamentali della sua ricchissima produzione, che gli è valsa il Nobel nel 2008. La premessa di Foucault, per cui il testo stesso dell'autore franco-mauriziano si configura come metafora dello spazio, dei suoi enjeux e limites, contribuisce da subito a definire l'intrinseca complessità della "metafora esotica" evocata nel titolo del lavoro di Thibault.

2 La visione della città post-moderna consegnata da Le Clézio materializza lo spettro di un luogo entropico e disumanizzato, dove la coscienza dell'individuo viene sovrastimolata e addormentata dai continui messaggi subliminali della pubblicità. Qui il personaggio tipo, nell'impossibilità di sottrarsi al controllo dei media, alla stregua di un grottesco burattino, finisce presto preda di manie di persecuzione che lo portano a intraprendere spostamenti e conversazioni estremamente contorti. Si individua quindi una duplice erranza: una si risolve nel vagare nella città labirintica e rende conto dello stato di smarrimento dell'uomo, ormai alla deriva; l'altra racconta di una corsa sfrenata attraverso il globo e mostra un processo di crescente appiattimento culturale, espressione di un passato coloniale ed effetto della globalizzazione, senza lasciare spazio ad alcuna lettura esotica o pittoresca.

3 L'erranza forsennata dei soggetti paranoidi messi in scena da Le Clézio incarna del resto la condizione di esilio vissuta nel mondo postmoderno dall'io frammentato, reso 
incapace di cogliere qualsivoglia visione totalizzante. A partire da tale considerazione e sulla base delle tesi di Mircea Eliade e di Carl Gustav Jung, si apre la strada ad un'interpretazione antropologica e psicanalitica del viaggio: non più visto solo come desolante fuga verso un ailleurs e un dehors, esso è concepito come coraggiosa ricerca della propria interiorità. In una prospettiva che ricorda da vicino lo sciamanesimo sperimentato da Artaud in Messico, attraverso la scrittura del viaggio Le Clézio predica la distruzione dell'ordine razionale e un ritorno dello spirito umano alla sua natura primordiale: la pensée mythique. Proprio l'inedita scelta lecleziana, oggetto dell'ultima sezione di questo lavoro, di far assumere all'esperienza catartica del viaggio le sembianze di una vera e propria profezia apocalittica mette in luce l'ennesima sfaccettatura di un universo finzionale estremamente composito, legato tanto al Nouveau Roman quanto alla mouvance della littérature-monde degli scrittori francofoni odierni. 